\title{
Conservação da Onça Parda (Puma Concolor) Como Tema Para a Educação ambiental no Entorno de Áreas Protegidas
}

\author{
Puma (Puma Concolor) Conservation As a Topic For Environmental Education in the \\ Surroundings of Protected Areas
}

\author{
Conservación de la Onza Parda (Puma Concolor) Como Tema Para la Educación \\ Ambiental en el Entorno de Áreas Protegidas
}

\author{
Mayla Willik Valenti ${ }^{1}$ \\ Haydée Torres de Oliveira² \\ Amadeu José Montagnini Logarezzi ${ }^{3}$
}

\begin{abstract}
Resumo
Os objetivos deste trabalho foram problematizar o tema da conservação da onça parda no entorno das Estações Ecológica e Experimental de Itirapina (SP) a partir da visão de pessoas envolvidas nesta realidade e, junto com elas, identificar as dimensões exclusoras e transformadoras de desenvolver ações de educação ambiental com base no tema. A pesquisa foi baseada na metodologia comunicativa crítica. Realizamos seis grupos focais comunicativos e duas entrevistas comunicativas, totalizando 25 pessoas com diferentes conexões com o tema de estudo. Identificamos que a parceria com pesquisadoras/es, a valorização da inteligência cultural e da dimensão instrumental podem aproximar a população da biodiversidade local. É preciso cuidar dos valores éticos e estéticos pelo fato desses animais participarem de conflitos com os seres humanos. Destacamos a importância de associar outros temas relevantes para a comunidade. Essas indicações podem inspirar ações educativas com outras espécies e em diferentes contextos.
\end{abstract}

Palavras-chave: Metodologia comunicativa crítica. Tema gerador. Unidades de conservação.

\begin{abstract}
This study aimed to problematize the topic of puma conservation in the surroundings of Ecological and Experimental Stations of Itirapina (SP) considering the impressions of people involved in this reality and, along with them, to identify exclusory and transformative dimensions to develop an environmental education program about this issue. The research was based on critical communicative methodology. We performed six communicative focus groups and two communicative interviews, totalizing 25 people differently related to the study's subject. We identified that partnerships with researchers, the appreciation of cultural intelligence and instrumental dimension can approximate people to local biodiversity. It is necessary to care about ethics and aesthetics values, because these animals are involved in conflicts with humans. We highlight the importance of associating other relevant topics to community. These indications can inspire educative actions with other species and in different contexts.
\end{abstract}

Keywords: Critical communicative methodology. Generative theme. Protected áreas.

\section{Resumen}

Los objetivos de este artículo fueron problematizar el tema de la conservación de la onza parda en el entorno de las Estaciones Ecológica y Experimental de Itirapina (SP) a partir de la visión de personas involucradas en esta realidad y, junto con ellas, identificar las dimensiones de exclusión y de transformación para desarrollarse acciones de educación ambiental sobre este tema. La investigación se basó en la metodología comunicativa

\footnotetext{
${ }^{1}$ Doutora em Ciências pelo Programa de Ecologia e Recursos Naturais da Universidade Federal de São Carlos. Sócia-fundadora, pesquisadora e educadora ambiental na Fubá - Educação Ambiental e Criatividade. E-mail: mayla@fubaea.com.br

${ }^{2}$ Professora Titular/Senior. Laboratório de Educação Ambiental, Departamento de Ciências Ambientais, Universidade Federal de São Carlos. E-mail: haydee.ufscar@gmail.com

3 Professor Titular/Senior. Departamento de Engenharia de Materiais, Departamento de Ciências Ambientais, Universidade Federal de São Carlos. E-mail: amadeulogarezzi@gmail.com
} 
crítica. Realizamos seis grupos focales comunicativos y dos entrevistas comunicativas, totalizando 25 personas con diferentes conexiones con el tema de estudio. Identificamos que la asociación con investigadoras e investigadores, la valorización de la inteligencia cultural y de la dimensión instrumental pueden aproximar a la población de la biodiversidad local. Es necesario cuidar de los valores éticos y estéticos por el hecho de que las onzas participen en conflictos con los seres humanos. Destacamos la importancia de asociar otros temas relevantes para la comunidad. Estas indicaciones pueden inspirar acciones educativas con otras especies y en diferentes contextos.

Palabras clave: Metodología comunicativa crítica. Tema generador. Áreas protegidas.

\section{Introdução}

Com base principalmente no conceito de diálogo de Freire e de ação comunicativa de Habermas, a aprendizagem dialógica é apresentada como forma de atender às mudanças sociais que vêm ocorrendo na sociedade da informação (AUBERT et al., 2008; BRAGA; GABASSA; MELLO, 2010; MELLO; BRAGA; GABASSA, 2012). O principal objetivo da aprendizagem dialógica é proporcionar novas formas de se relacionar com o mundo e de educar. Dessa maneira, ela busca diminuir as desigualdades sociais, às quais grande parte da população está submetida, fornecendo instrumentos para a inserção social e educativa (AUBERT et al., 2008; GÓMEZ et al., 2006).

Apesar de muitos elementos da aprendizagem dialógica serem compartilhados pelas tendências críticas da educação ambiental (SANT'ANA, 2011), existem poucos estudos que aproximem esses dois campos do conhecimento, dentre eles Logarezzi (2006, 2009, 2010), Ribeiro (2009), Ribeiro, Sant'Ana e Logarezzi (2012) e Sant'Ana (2011). As tendências críticas da educação ambiental apostam no potencial de (re)construção ou transformação da realidade e emancipação dos sujeitos (DREYFUS; WALS; VAN WEELIE, 1999; GUIMARÃES, 2004; WALS; DILLON, 2013). Para tanto, a prática educativa deve estar baseada no diálogo igualitário e ser pensada e estruturada com a comunidade, buscando melhores condições sociais e ambientais, a partir de argumentações baseadas em pretensões de validez e não de poder. Portanto, em uma prática de educação ambiental dialógico-crítica, as pessoas envolvidas são protagonistas de seu processo de aprendizagem (LOGAREZZI, 2006, 2009, 2010; RIBEIRO; SANT'ANA; LOGAREZZI, 2012; SANT'ANA, 2011).

Seguindo princípios da educação ambiental crítica e transformadora, Tozoni-Reis (2006) propõe que os temas ambientais locais sejam usados como temas geradores em ações de educação ambiental. Em seu livro Pedagogia do oprimido, Freire (2005) propõe o trabalho com temas geradores visando incorporar situações concretas, presentes e existenciais no conteúdo programático de uma ação educativa. Nesse sentido, há uma articulação radical entre conhecimento e ação, na medida em que os temas geradores propiciam uma compreensão mais crítica e contextualizada da realidade vivida, a partir do diálogo no processo educativo (TOZONI-REIS, 2006). Dessa maneira, em coerência com seu entendimento dialógico do mundo e da educação, Freire (2005) defende que o diálogo esteja presente desde o planejamento do conteúdo a ser abordado em uma prática educativa.

Para a realização da investigação dos temas geradores, Freire (2005) indica uma metodologia específica com base no diálogo com as pessoas que participarão de determinada ação educativa. Contudo, o estudo que apresentamos neste artigo tem uma abordagem diferente desta proposta, já que se propõe analisar as potencialidades de implantar um programa de educação ambiental no entorno de duas áreas protegidas sobre um tema preestabelecido. Apesar disso, consideramos que nosso enfoque é coerente com a educação dialógica proposta por Freire (2005), na medida em que o uso do tema da conservação da onça parda em ações de educação ambiental foi abordado de forma dialógica. Este tema foi escolhido em decorrência da preocupação do campo científico da biologia da conservação 
com a manutenção de populações viáveis desta espécie no interior do estado de São Paulo. Assim, a partir de uma perspectiva comunicativa, nossa intenção foi analisar a pertinência de trabalhar este tema com a comunidade local. Portanto, os objetivos deste trabalho foram problematizar o tema da conservação da onça parda no entorno de duas áreas protegidas em Itirapina (SP), a partir da visão de pessoas envolvidas nesta realidade e, junto com elas, identificar as dimensões exclusoras e transformadoras de desenvolver ações de educação ambiental com base no tema.

\section{Contexto da pesquisa}

A conservação de animais predadores de topo de cadeia é um tema fundamental para a conservação da biodiversidade (RIPPLE et al., 2013; SERGIO et al., 2008; SIMBERLOFF, 1998). Em um território com alta fragmentação de habitats naturais e com poucos remanescentes de vegetação nativa, as áreas protegidas exercem papel fundamental na conservação de espécies predadoras de topo de cadeia. No interior do estado de São Paulo, as áreas protegidas abrigam importante parcela da biodiversidade associada à Floresta Estacional Semidecídua e ao Cerrado (BATALHA; MANTOVANI, 2000; SÃO PAULO, 2008; TALAMONI; MOTTA JUNIOR; DIAS, 2000). Espécies de grandes carnívoros, como a onça parda (Puma concolor), utilizam essas unidades para sobreviverem e se reproduzirem. Ao mesmo tempo, suas populações têm sido ameaçadas pela redução de habitats, atropelamentos e conflitos com seres humanos (MIOTTO et al., 2011, 2012).

Apesar de existirem muitas iniciativas de educação ambiental em áreas protegidas, as unidades de conservação da região central do interior paulista apresentam dificuldades para desenvolver ações, especialmente com o público não escolar. Diferentemente de outras unidades de conservação no país, estas não possuem problemas de regularização fundiária ou moradores irregulares. Além disso, também não há populações tradicionais, como quilombolas, caiçaras ou indígenas que dependam do extrativismo nessas áreas para sobreviver, como ocorre em outros locais. Disso decorre uma maior dificuldade de aproximação com a comunidade do entorno, especialmente o público adulto (VALENTI $e t$ $a l .$, 2014). Essas características, juntamente com limitações estruturais e de equipe, tornam a realização de ações educativas com a população local um desafio para muitas unidades do interior paulista (MENARIN, 2009; SANTOS et al., 2000; VALENTI, 2010; VALENTI et al., 2014, VALENTI; OLIVEIRA; LOGAREZZI, 2017).

Com base em diagnóstico preliminar (VALENTI et al., 2014), selecionamos a Estação Ecológica e a Estação Experimental de Itirapina como áreas de estudo por apresentarem características relevantes para a conservação da onça parda. Além disso, devido às dificuldades para desenvolver um programa de educação ambiental com a comunidade do entorno. O município de Itirapina está localizado no centro do estado de São Paulo e possui aproximadamente 15 mil habitantes. A Estação Ecológica (Latitude $22^{\circ} 11^{\prime}$ a $22^{\circ} 15^{\prime} \mathrm{S} /$ Longitude $47^{\circ} 51^{\prime} \mathrm{e} 48^{\circ} 00^{\prime} \mathrm{W}$ ) é classificada como unidade de conservação de proteção integral e compreende um importante remanescente de cerrado. A Estação Experimental (Latitude $22^{\circ} 15^{\prime}$ a $22^{\circ} 15^{\prime}$ S/Longitude $47^{\circ} 45^{\prime}$ e $47^{\circ} 51^{\prime} \mathrm{W}$ ) é uma categoria de área protegida exclusiva do estado de São Paulo que se assemelha às categorias de uso sustentável estabelecidas pelo Sistema Nacional de Unidades de Conservação (BRASIL, 2000). Esta área abriga áreas de cerrado e de silvicultura. As duas são adjacentes e contíguas à área urbana, e possuem plano de manejo integrado (SÃO PAULO, 2006). Em diálogo com pesquisadoras(es) que trabalhavam nas áreas protegidas, identificamos que Itirapina é um dos poucos municípios da região que ainda abriga pequenas propriedades com criação de animais no interior de São Paulo, onde poderiam ocorrer conflitos entre proprietárias(os) e onças. Além disso, há registro de aparecimento de uma onça na área urbana e de atropelamentos 
desta espécie nas estradas que passam pelo município.

\section{Procedimentos metodológicos}

Este estudo teve como referenciais teórico-metodológicos a aprendizagem dialógica (AUBERT et al., 2008; FLECHA, 1997; MELLO; BRAGA; GABASSA, 2012) e a metodologia comunicativa crítica (GÓMEZ et al., 2006; GÓMEZ; PUIGVERT; FLECHA, 2011). Dessa maneira, partimos do pressuposto de que a realidade social é intersubjetiva. Sendo assim, os procedimentos metodológicos se pautaram em um processo de entendimento estabelecido por meio do diálogo entre as pessoas envolvidas no contexto estudado. Essa orientação metodológica pretende não apenas descrever ou explicar a realidade, mas, neste mesmo processo, também transformá-la, com ênfase na busca dialógica de entendimento em direção ao consenso (GÓMEZ et al., 2006; GÓMEZ; PUIGVERT; FLECHA, 2011).

As(os) participantes da pesquisa foram convidadas(os) por terem alguma relação com o tema da educação ambiental e/ou da conservação da onça parda nas Estações Ecológica e Experimental de Itirapina e no seu entorno. Procuramos incluir pessoas com diferentes perspectivas e graus de proximidade com a realidade local e com as questões relacionadas à conservação da biodiversidade. Assim, dialogamos com educadoras(es) e técnicas(os) das Estações Ecológica e Experimental de Itirapina e da Fazenda da Toca. A Fazenda da Toca é uma propriedade voltada à produção de alimentos orgânicos localizada no município e que abrigava o Instituto Toca, responsável por projetos de educação, saúde, cultura e meio ambiente. Também conversamos com funcionárias(os) que se dedicam à manutenção das áreas protegidas e com trabalhadoras(es) rurais da Fazenda da Toca, além de um proprietário rural e um trabalhador rural que tiveram problemas com a predação de animais de criação pela onça. De junho de 2012 a dezembro de 2013, realizamos seis entrevistas com base na técnica de grupos focais comunicativos e duas entrevistas comunicativas (GÓMEZ et al., 2006; GÓMEZ; PUIGVERT; FLECHA, 2011), envolvendo um total de 25 pessoas, reunidas de acordo com seu histórico de trabalho conjunto, seguindo as indicações da metodologia comunicativa crítica (Tabela 1). Todas(os) as(os) participantes foram informadas(os) sobre os objetivos do trabalho e assinaram o Termo de Consentimento Livre e Esclarecido, conforme recomendações do Comitê de Ética em Pesquisa com Seres Humanos da UFSCar, que aprovou nosso projeto.

Tabela 1 - Participantes da pesquisa sobre o uso do tema da conservação da onça parda para a educação ambiental no entorno de duas áreas protegidas em Itirapina (SP). GFC = grupo focal comunicativo e EC = entrevista comunicativa

\begin{tabular}{|c|c|}
\hline $\begin{array}{l}\text { Coleta } \\
\text { dados }\end{array}$ & Participantes \\
\hline GFC 1 & $\begin{array}{l}\text { Um pesquisador científico em educação ambiental e um analista } \\
\text { ambiental com ênfase em educação ambiental, ambos funcionários do } \\
\text { Instituto Florestal, órgão estadual responsável pelas áreas protegidas } \\
\text { de Itirapina; e o coordenador de um projeto social desenvolvido em } \\
\text { parceria com as áreas. }\end{array}$ \\
\hline GFC 2 & $\begin{array}{l}\text { Uma estudante e um estudante de doutorado em Ecologia que } \\
\text { desenvolveram ações de educação ambiental nas áreas protegidas de } \\
\text { Itirapina. }\end{array}$ \\
\hline GFC 3 & Uma pesquisadora científica e chefe da unidade, funcionária do \\
\hline
\end{tabular}


Instituto Florestal e moradora de Itirapina há muitos anos; e um estudante de graduação em engenharia ambiental que desenvolveu projeto de iniciação científica sobre a percepção da população sobre a onça parda e que é morador de Itirapina.

Dois educadores e duas educadoras de uma escola infantil e de um GFC 4 projeto com adolescentes promovidos pelo Instituto Toca, sendo uma delas moradora de Itirapina; e uma técnica em meio ambiente e educação ambiental, funcionária do Instituto Toca.*

Dois funcionários e uma funcionária das áreas protegidas de Itirapina

GFC 5 responsáveis pela manutenção das áreas; e uma funcionária de um projeto social desenvolvido na área da Estação Experimental; todas/os moradores muito antigos ou nascidos na cidade de Itirapina.

Quatro funcionários técnicos do setor de pesquisa e desenvolvimento GFC 6 da Fazenda da Toca, sendo um gestor e um estagiário; um trabalhador e duas trabalhadoras rurais, funcionárias/os da Fazenda da Toca, que moram há três anos na própria fazenda.*

EC 1 Um produtor rural em Itirapina, envolvido com projetos pela onça parda.

Um trabalhador rural que já foi funcionário de várias propriedades em

EC 2

Itirapina e presenciou vários casos de ataques da onça parda a animais de criação.

*No GFC 4, a técnica em meio ambiente e educação ambiental não participou do segundo encontro para validação dos dados. No GFC 6, o gestor, o estagiário, um dos técnicos e uma trabalhadora rural não participaram do segundo encontro para validação dos dados.

Fonte: Valenti, Oliveira e Logarezzi (2015)

Em todo o procedimento de coleta de dados, buscamos a interlocução e o entendimento entre as(os) participantes. No processo de entendimento, são considerados os argumentos apresentados e não as posições de poder ocupadas pelas pessoas envolvidas. Além disso, todos os argumentos são suscetíveis de crítica, o que, justamente, permite que possam ser validados pelo grupo. O papel da investigadora, primeira autora deste artigo, foi conduzir o processo dialógico e incluir no diálogo aspectos teóricos do campo da educação ambiental e da aprendizagem dialógica, além de sua experiência como pesquisadora e educadora ambiental (GÓMEZ et al., 2006; GÓMEZ; PUIGVERT; FLECHA, 2011). No primeiro encontro com cada grupo ou pessoa, dialogamos sobre as dimensões exclusoras e transformadoras de implantar com a comunidade um programa de educação ambiental voltado à conservação da onça parda. Entre as questões apresentadas, perguntamos às/aos participantes sobre a pertinência do uso da conservação da onça parda como tema para a educação ambiental na região. As respostas foram a base dos resultados apresentados neste artigo. Porém, também selecionamos outros trechos dos diálogos para compor os resultados da pesquisa.

Os diálogos foram gravados em áudio, transcritos e sistematizados de acordo com os objetivos e com as bases teórico-metodológicas do estudo, sendo separados inicialmente em dimensões exclusoras e transformadoras. Nas dimensões exclusoras, identificamos pontos negativos, limites e dificuldades e, nas dimensões transformadoras, identificamos aspectos positivos, potencialidades e sugestões para o uso do tema da conservação da onça parda em processos de educação ambiental. Os dados coletados em cada grupo focal ou entrevista 
foram interpretados pela pesquisadora e sintetizados em parágrafos. Os parágrafos sintéticos foram apresentados às(aos) respectivas(os) participantes para serem validados, conforme indica a metodologia comunicativa crítica (GÓMEZ et al., 2006; GÓMEZ; PUIGVERT; FLECHA, 2011). Neste momento, as(os) participantes acrescentaram ideias e informações, contribuíram para a interpretação dos conteúdos registrados e elaboraram junto com a pesquisadora parágrafos em consenso.

Depois desse processo, tais parágrafos foram organizados seguindo a proposta de Carvalho (2006). Segundo este autor, uma forma de abordar a complexidade das questões ambientais é incorporar ao planejamento e à prática das ações de educação ambiental as dimensões dos conhecimentos, dos valores éticos e estéticos e da participação e cidadania (CARVALHO, 2006). Neste artigo, denominamos essas dimensões de categorias para evitar confusão com a classificação em dimensões exclusoras e transformadoras. Na categoria dos "conhecimentos", incluímos parágrafos que se remetiam aos conhecimentos científicos e populares, ao conhecimento instrumental e à relação do tema com outros tópicos. $\mathrm{Na}$ categoria dos "valores éticos e estéticos", classificamos os parágrafos que tratavam de sentimentos, valorização da biodiversidade e diferentes formas de contato com os animais e seus ambientes. Na categoria de "participação e cidadania", agrupamos os parágrafos que abordavam aspectos locais que indicavam a relevância do tema para a comunidade, o que poderia subsidiar ações sobre problemas concretos. É importante destacar que, na proposta de Carvalho (2006), a dimensão política da educação ambiental aparece como elemento articulador entre conhecimentos, ética e estética e participação. Dessa forma, buscamos discutir os dados encontrados em todas as categorias buscando uma interpretação crítica da realidade, elaborada junto com as(os) participantes da pesquisa.

Finalmente, sintetizamos os parágrafos em consenso a fim de facilitar sua representação e entendimento, indicando quais grupos focais e entrevistas comunicativas contribuíram para a composição daquela síntese (tabelas 2, 3 e 4). Posteriormente, relacionamos cada dimensão exclusora a uma dimensão transformadora, de modo a evidenciar as possibilidades de transformação para os problemas encontrados.

\section{Resultados e discussão}

Em relação à categoria dos conhecimentos, os resultados obtidos indicam que a conservação da onça parda e de outros animais é um tema pouco trabalhado em ações educativas na região estudada (Tabela 2). De fato, o número de trabalhos que relatam pesquisas e experiências voltadas diretamente à conservação de animais predadores é pequeno, tanto no Brasil (e.g. ARAÚJO; KRAEBER; MURTA, 2011; BIZERRIL; SOARES; SANTOS, 2011) como em outros países (e.g. ALEGRE, 2007; BARREDA-LEYVA, 2010; CURTI; VALDEZ, 2009; ESPINOSA; JACOBSON, 2011; VAN DER PLOEG, ARANO, VAN WEERD, 2011; VAN DER PLOEG et al., 2011). Apesar disso, a presença de áreas naturais foi indicada como potencialidade para abordar este tema, já que propiciam o contato direto com o habitat dos animais. Além disso, a parceria com pesquisadoras(es) que realizam coleta de dados nessas áreas foi indicada como uma possibilidade de aproximar a população da biodiversidade local (Tabela 2).

Tabela 2 - Síntese das dimensões exclusoras e transformadoras relacionadas à categoria dos conhecimentos sobre o uso da conservação da onça parda como tema para a educação ambiental no entorno de duas unidades de conservação em Itirapina (SP). GFC = grupo focal comunicativo e EC = entrevista comunicativa

\section{Dimensões exclusoras Dimensões transformadoras}


O tema da conservação de Os ambientes naturais das unidades de conservação predadores de topo de cadeia é e das áreas rurais favorecem abordar o tema da pouco trabalhado (GFC 1, GFC conservação da fauna, pois propiciam o contato 4) direto com o habitat dos animais. Além disso, a divulgação de pesquisas e seus resultados, e de eventos como a soltura de onças feitas na região aproximam as pessoas do tema a partir da biodiversidade local (GFC 1, GFC 4).

Existem informações úteis sobre o comportamento da onça parda e sobre como lidar com esses animais em um possível encontro que não são difundidas para a população em geral e nem para as/os funcionárias/os das unidades de conservação (GFC 1, GFC 4, GFC 6, EC 1).

A parceria entre pesquisadoras/es e as unidades de conservação pode ajudar a difundir esse tipo de informação e instrumentalizar a comunidade sobre os reais riscos proporcionados pela onça e como proceder em um encontro com o animal. É mais provável que as pessoas tenham ações para a conservação da onça estando mais bem informadas. Esse conhecimento é especialmente importante para as populações rurais, que têm contato maior com animais silvestres (GFC 1, GFC 4, GFC 6, EC 1, EC 2).

Ao trabalhar os temas ambientais, A educação ambiental deve abordar os é preciso tomar cuidado para não conhecimentos biológicos relacionados à onça abordar a natureza como algo parda evidenciando suas interações e funções intocável (GFC 4). ecológicas na natureza e como isso interfere nos ambientes rurais e urbanos, além de apresentar soluções para melhorar a convivência entre as pessoas e os animais, como formas alternativas de produção de alimentos. A partir dessa abordagem, pode-se ampliar o diálogo para a conservação do cerrado e da biodiversidade em geral. Para trabalhar com todos esses temas, seria importante que as/os educadoras/es tivessem uma formação maior sobre o assunto (GFC 1, GFC 4, GFC 6).

Os conhecimentos tradicionais sobre a vida no campo foram sendo perdidos ao longo do tempo, especialmente pela invasão de grandes empresas no campo e pela falta de contato com os ambientes rurais provocadas pelo êxodo rural (GFC 5 e EC 1).
O conhecimento tradicional das pessoas que vivem no campo geralmente está associado a ações de conservação. Aproximar os conhecimentos e experiências das pessoas do campo com os conhecimentos científicos deveria ser um dos objetivos principais para a educação ambiental (EC 1, EC 2).

Realmente, a parceria entre pesquisadoras(es) e educadoras(es) parece ser um caminho pertinente para o desenvolvimento da educação ambiental e para a conservação da biodiversidade. Muitos artigos publicados sobre esse tema (e.g. ALEGRE, 2007; BARREDA- 
LEYVA, 2010; BENITES; MAMEDE, 2008; CURTI; VALDEZ, 2009; ESPINOSA; JACOBSON, 2011; PADUA, 2010) mostram justamente este movimento de percepção da necessidade de incluir ações educativas em projetos de pesquisa e/ou de conservação que inicialmente seriam apenas biológicos. Portanto, a prática tem mostrado às(aos) pesquisadoras(es) que a pesquisa e o manejo baseados apenas em intervenções técnicas não são suficientes e que intervenções comunicativas, como programas de educação ambiental, também são fundamentais para a conservação da biodiversidade (CASTILLO, 2003).

A parceria com pesquisadoras(es) também foi indicada como possibilidade para difundir informações úteis para a população sobre o comportamento das onças, os riscos que elas oferecem e como se comportar diante de uma ocorrência com o animal (Tabela 2). Outros conhecimentos sobre as relações ecológicas das onças, sua influência nas atividades humanas, soluções para melhorar a convivência com esses animais e, ainda, a relação deste tema com tópicos mais amplos foram indicados como relevantes para o trabalho de educação ambiental voltado à conservação da espécie. Dessa forma, seria evitada a emissão de uma ideia de natureza intocável, evidenciando os aspectos biológicos, sociais, econômicos e culturais do ambiente e considerando suas múltiplas e complexas relações (GUIMARÃES, 2001; LOGAREZZI, 2010; SANT'ANA, 2011).

Nesse sentido, percebemos a importância do conhecimento instrumental ao trabalhar com o tema da conservação de predadores. A dimensão instrumental é um princípio da aprendizagem dialógica definido pelos conhecimentos necessários para a sobrevivência e para a integração das pessoas na atual sociedade da informação (AUBERT et al., 2008; BRAGA; GABASSA; MELLO, 2010; FLECHA, 1997; MELLO; BRAGA; GABASSA, 2012). Por exemplo, a informação de que a onça parda não costuma ter um comportamento agressivo e que os registros de ataque a seres humanos são muito raros poderia tranquilizar as pessoas que trabalham no campo e incentivar reflexões e ações mais conservacionistas em relação à espécie. Existe uma tendência no discurso da educação ambiental crítica de se opor às atividades focadas em conteúdos ecológicos, por defender que é necessário mais do que ter acesso a informações para agir de forma mais sustentável. Porém, é preciso tomar cuidado para não negligenciar a dimensão dos conhecimentos, sob o risco de negar acesso ao conhecimento acadêmico às pessoas que já vivem afastadas desta produção intelectual, além de exercitar um diálogo sem conteúdo e reduzido em seu potencial transformador (MELLO; BRAGA; GABASSA, 2012).

Ao mesmo tempo, o diálogo entre o conhecimento científico e o conhecimento popular foi indicado pelas(os) participantes como um dos principais objetivos da educação ambiental. Em Itirapina, o processo de urbanização é relativamente recente. Assim, as perdas do conhecimento tradicional devido ao êxodo rural são percebidas pelas pessoas que acompanharam esse processo. Porém, as pessoas que permanecem no campo ainda cultivam conhecimentos associados a ações de conservação da biodiversidade, inclusive reconhecendo a importância das onças na natureza (Tabela 2). Esses resultados nos remetem a outro princípio da aprendizagem dialógica, a inteligência cultural. Segundo Flecha (1997), a inteligência acadêmica é supervalorizada na sociedade atual. Porém, existem muitas outras formas de conhecimento e habilidades práticas desenvolvidas ao longo da vida de cada pessoa que são geralmente desvalorizadas. Contrariando essa tendência, tanto a aprendizagem dialógica como a educação ambiental apresentam argumentos para a valorização dos diferentes saberes e o reconhecimento da capacidade de todas as pessoas para aprender, ensinar, dialogar e contribuir com a busca de soluções e o planejamento de ações educativas (BRAGA; GABASSA; MELLO, 2010; LOGAREZZI, 2009; OLIVEIRA, 2005).

Em relação aos valores éticos e estéticos, foi interessante notar que a preocupação com aspectos dessa categoria aparece com bastante frequência em quase todas as coletas de dados (tabela 3). Considerando que a educação ambiental surgiu em um contexto de questionamento 
de valores, buscando um posicionamento ético, é evidente a importância de incorporar essa dimensão nos processos educativos de modo intencional (BONOTTO, 2008; CARVALHO, 2006; IARED; OLIVEIRA, 2013; MARIN; OLIVEIRA; COMAR, 2003; MARIN; SILVEIRA, 2009; WALS, 1999). O tema da conservação de predadores, como a onça, exige cuidado especial com esses aspectos por eles estarem envolvidos em conflitos com os seres humanos e, ao mesmo tempo, por serem animais bastante carismáticos.

Tabela 3 - Síntese das dimensões exclusoras e transformadoras relacionadas à categoria dos valores éticos e estéticos sobre o uso da conservação da onça parda como tema para a educação ambiental no entorno de duas unidades de conservação em Itirapina (SP). $\mathrm{GFC}=$ grupo focal comunicativo e EC = entrevista comunicativa

\section{Dimensões exclusoras}

$\mathrm{O}$ medo que as pessoas têm das onças pode afastar as pessoas do trabalho educativo sobre esse tema (GFC 4, GFC 5, GFC 6, EC 1, EC 2).

\section{Dimensões transformadoras}

As diferentes percepções em relação a esses animais precisam ser consideradas em um trabalho educativo. Apesar do medo que as pessoas sentem, as onças também geram muita curiosidade e admiração em todas as faixas etárias. $\mathrm{O}$ medo não é motivação para caçar o animal (GFC 1, GFC 2, GFC 4, GFC 5, EC 2).

Por não ser uma espécie diretamente útil ao ser humano e, ao contrário, por causar prejuízos econômicos e trazer alguns riscos, a conservação da onça pode não ser valorizada pelas pessoas em geral e, principalmente, pelos adultos (GFC 2, GFC 3, GFC 4).

A educação ambiental deve trabalhar com as diferentes formas de valorizar a biodiversidade, não apenas pela sua utilidade, mas também pela sua beleza e pelo aspecto ético de direito à vida de todos os seres. Apresentar as relações ecológicas de uma espécie como a onça pode contribuir para a melhor compreensão do papel de cada ser e até evidenciar conexões inesperadas. $\mathrm{O}$ contato com o ambiente natural proporciona reflexões e sensações que podem proporcionar mudanças de valores sobre a biodiversidade (GFC 2, GFC 4, GFC 5, GFC 6).

O contato direto com a onça parda é muito raro, o que pode desmotivar a participação em ações educativas sobre esse tema (GFC 1, GFC 4, GFC 5, GFC 6).
Apesar de raro, as pessoas que têm mais contato com ambientes naturais e que vivem nas áreas rurais têm mais chance de avistar a onça e outros animais silvestres. A onça pode ser vista também pelas pessoas que vivem na cidade, pois um indivíduo foi encontrado em uma árvore em um bairro urbano. Além disso, é comum encontrar vestígios, como pegadas, marcas em árvores e pelos que indicam a presença do animal. Esses vestígios podem ser usados como recursos didáticos (GFC 1, GFC 2, GFC 5, EC 1, EC 2). 
ações educativas podem causar as pessoas conheçam melhor as onças. Os sensações negativas nas pessoas animais taxidermizados e a observação de (GFC 2, GFC 6). animais vivos no zoológico permitem um contato próximo com o animal. A exposição de fotos e vídeos também pode chamar a atenção das pessoas. As imagens podem ser feitas pela própria comunidade. É importante que esses recursos sejam interativos e provoquem a reflexão (GFC 1, GFC 2, GFC 4, GFC 5, GFC $6)$.

O medo da onça foi indicado recorrentemente como uma das dificuldades para trabalhar com o tema. A preocupação com os riscos que esses animais trazem é comum em todas as pessoas, mesmo naquelas que defendem a sua conservação. Como dimensão transformadora em relação a esse aspecto, encontramos a curiosidade e a admiração que esses animais também geram (Tabela 3). Essa admiração parece desmotivar a caça das onças, a não ser pelo prejuízo econômico que causam. Esse resultado contraria o estudo de Marchini e MacDonald (2012), que encontraram questões pessoais, sociais e o sentimento de medo como motivações para as pessoas matarem a onça pintada no Pantanal e na Amazônia. Em nossos diálogos, a única motivação relatada para a caça da onça parda foi o prejuízo econômico que elas causam (Tabela 3 ).

Por outro lado, dialogamos sobre a possibilidade de algumas pessoas não valorizarem as onças por não se tratar de uma espécie diretamente útil ao ser humano e, ao contrário, por causar prejuízos econômicos e trazer riscos (Tabela 3). Essa preocupação é comum ao desenvolver ações de conservação voltadas para animais predadores (VAN DER PLOEG; ARANO; VAN WEERD, 2011). No entanto, Van der Ploeg, Arano e Van Weerd (2011) e Van der Ploeg et al. (2011) sugerem que os argumentos sobre o valor intrínseco dos seres vivos são melhores para promover a conservação de uma espécie, mesmo em comunidades em situação de pobreza. É comum que pesquisadoras(es) e governantes esperem que essas comunidades se interessem mais por argumentos utilitaristas, como os ganhos econômicos que a espécie pode trazer. Porém, segundo as(os) autoras(es), essa ideia reduz a comunidade à pobreza, como se aquelas pessoas não fossem nada além de pessoas pobres. Assim, não se considera sua história, identidade, cultura, necessidade e capacidade de se conectar à natureza. Portanto, a verdadeira comunicação, cuja reciprocidade é inerente, é indispensável para compreender e transformar as relações socioambientais (FREIRE, 1977; LOGAREZZI, 2006, 2010; SANT’ANA, 2011).

Em nossos resultados, o contato com o ambiente natural apareceu como forma de proporcionar reflexões e sensações que podem gerar mudanças de valores sobre a biodiversidade. Em vários diálogos com as(os) participantes, surgiu a defesa de que a educação ambiental deve abarcar diferentes formas de valorizar a biodiversidade, incluindo a discussão de aspectos éticos, como o direito à vida de todos os seres (Tabela 3). Segundo Oksanen (1997), o resgate dos valores intrínsecos da biodiversidade é necessário para a superação da visão utilitarista e antropocêntrica presente em muitos discursos atuais. Nesse sentido, Van der Ploeg, Arano e Van Weerd (2011) e Van der Ploeg et al. (2011) mostraram que o amor, o respeito, o orgulho e a curiosidade foram os melhores argumentos, se não os únicos, para promover a conservação dos crocodilos das Filipinas em uma comunidade rural daquele país. Da mesma forma, acreditamos que esses valores devem ser trabalhados em ações educativas voltadas à conservação das onças pardas e de qualquer outra espécie. 
O contato mais próximo com os animais foi sugerido como estratégia para desenvolver ações educativas sobre as onças. Apesar de ser muito difícil observá-las, a população que vive na área rural e que passa bastante tempo em campo, como funcionárias(os) das áreas protegidas, tem maior probabilidade de encontrar esses animais (Tabela 3). Em 2010, a onça pôde ser vista também pelas pessoas que vivem na cidade, pois um indivíduo foi encontrado em uma árvore em um bairro urbano de Itirapina. Além disso, é comum encontrar vestígios, como pelos, pegadas e marcas em árvores, o que indica a presença do animal. Foi sugerido que esses vestígios podem ser usados como recursos didáticos (Tabela 3). Myers Jr e Saunders (2002) defendem que o contato dos seres humanos com os animais promove uma ponte para que as pessoas se preocupem com a conservação do ambiente como um todo. Nesse sentido, dialogamos sobre o uso de animais taxidermizados para propiciar esse contato mais próximo, além do uso de imagens e vídeos ou, ainda, de observar o animal vivo em zoológicos. É interessante notar que esses recursos permitem uma apreciação estética da onça, tanto ao apreciar a sua beleza quanto de percebê-la usando outros sentidos, como o tato, ao tocar um animal taxidermizado. Segundo Marin e Silveira (2009), a dimensão estética compreende todas as experiências que colocam os sujeitos em imersão no mundo e, assim, faz deles seres sociais e culturais. Por exemplo, a proposta de a própria comunidade fotografar a biodiversidade local e elaborar uma exposição propicia o exercício da apreciação estética do ambiente em que vivem e a reflexão sobre a sua conservação a partir dessa experiência, que é compartilhada com o público da exposição. Essa atividade foi realizada por um funcionário da Fazenda da Toca e também em uma ação educativa com funcionárias(os) das Estações Ecológica e Experimental de Itirapina (FELGA; VALENTI; OLIVEIRA, 2013).

Na categoria de "participação e cidadania", foi indicado que as áreas protegidas muitas vezes não são associadas à existência e à conservação da onça pela população (Tabela 4).

Tabela 4 - Síntese das dimensões exclusoras e transformadoras relacionadas à categoria da "participação e cidadania" sobre o uso da conservação da onça parda como tema para a educação ambiental no entorno de duas unidades de conservação em Itirapina (SP). $\mathrm{GFC}=$ grupo focal comunicativo e $\mathrm{EC}=$ entrevista comunicativa

Dimensões exclusoras
As unidades de conservação muitas vezes
não são associadas à existência e à
conservação da onça pela população
(GFC3).

\section{Dimensões transformadoras}

Realizar educação ambiental voltada à conservação da fauna faz parte dos objetivos institucionais das unidades de conservação. Este trabalho pode ajudar a mudar a percepção das pessoas de que a produção florestal é a principal atividade das unidades, mostrando seu papel na conservação da biodiversidade (GFC 1, GFC 2).

Muitas pessoas têm interações negativas com a fauna local. As soluções que deveriam ser apresentadas às pessoas que têm conflitos com onças não são tão simples de serem implementadas. Por isso, muitas vezes, as pessoas não veem outra solução a não ser matar a onça que
A população de Itirapina interage com as onças e outros animais de diferentes maneiras. Algumas pessoas têm conflitos com predadores, uma onça parda já foi avistada na cidade, muitos animais são atropelados nas rodovias do entorno. Assim, uma ação educativa sobre a 
está causando problema (GFC 1, GFC 2, conservação das onças parte de problemas GFC 3, EC 2).

concretos da comunidade. Ao mesmo tempo, é preciso lembrar que, embora a educação ambiental e o manejo de espécies possam e devam estar associados, a educação deve estabelecer um diálogo com as pessoas sobre o tema (GFC 1, GFC 2, GFC 3, GFC 5, EC 1).

Assim, um trabalho educativo voltado à conservação da fauna poderia contribuir para a mudança dessa percepção, permitindo o entendimento de todos os objetivos das áreas protegidas. De fato, realizar educação ambiental voltada à conservação da fauna faz parte dos objetivos das unidades de conservação e é uma responsabilidade dos órgãos ambientais que administram as unidades (Tabela 4). Para impulsionar ações nesse sentido, a esperança nas transformações necessárias precisa de referências práticas para que tais ações venham a se tornar concretas historicamente (FREIRE, 1992). Percebemos também que muitas pessoas têm interações negativas com a fauna local. Além disso, uma ação educativa com a comunidade rural deveria incluir a apresentação e o diálogo sobre possíveis soluções para os conflitos com esses animais. Porém, geralmente essas soluções exigem gastos incompatíveis com a realidade econômica existente, como a instalação de cercas elétricas, viveiros protegidos ou o uso de cães de condução adestrados. Nesse sentido, os órgãos ambientais responsáveis pela conservação da biodiversidade não têm conseguido apoiar as(os) produtoras(es) rurais na solução dos conflitos com animais predadores no contexto estudado. Por isso, muitas vezes, as pessoas não veem outra solução senão matar a onça que está causando problema (Tabela 4).

Pela presença destes e de outros impactos negativos sobre a população de onças, como os atropelamentos e até o aparecimento destes animais em áreas urbanas, identificamos que a conservação das onças pardas é um tema pertinente à realidade estudada (Tabela 4). No entanto, ficou evidente a existência de muitos outros temas relevantes para a comunidade e para a conservação de outras espécies da região em todos os grupos focais e entrevistas comunicativas que realizamos. Foram citados incêndios, recuperação de áreas degradadas, prejuízos causados por javalis, a conservação do cerrado, das matas ciliares, da ema e do cajuzinho-do-cerrado (Tabela 4). Então, ao desenvolver uma ação educativa voltada à conservação de apenas uma espécie, é preciso que este tema seja tratado de forma contextualizada, relacionando aquela espécie a outras questões relevantes para a comunidade local e ampliando a abordagem para temas mais gerais. Como sugere Freire (2005), este processo deve revelar as relações ser humano-mundo, superando a curiosidade ingênua e transformando-a em curiosidade epistemológica (FREIRE, 1996, 2001). Dessa maneira, espera-se que os temas problematizados na ação educativa desafiem as pessoas e exijam respostas em nível intelectual, mas também no nível da ação (FREIRE, 2005). Portanto, a compreensão da realidade socioambiental pode "começar a mudar a partir da mudança do concreto" (FREIRE, 1992, p. 27).

\section{Considerações finais}

Este artigo apresentou potencialidades e cuidados necessários ao trabalhar com o tema da conservação da onça parda no entorno de duas áreas protegidas na região central do estado de São Paulo. Identificamos a importância de abordar conhecimentos instrumentais 
associados à espécie e suas relações com os seres humanos e de aproximar os conhecimentos científicos dos conhecimentos populares por meio do diálogo igualitário. Também percebemos a necessidade de abordar a dimensão dos valores éticos e estéticos da biodiversidade, com cuidado especial para a questão do medo causado pelas onças e da valorização intrínseca dessa espécie, apesar dos riscos e prejuízos que traz. Finalmente, destacamos a importância de difundir para a comunidade rural soluções práticas que evitem os conflitos com esses animais e de contextualizar e relacionar a conservação da onça parda com outros temas relevantes para a comunidade. Acreditamos que essas indicações possam ser extrapoladas para o trabalho com outras espécies de animais predadores e podem ser consideradas ao planejar ações educativas em outros contextos, especialmente se forem baseados no diálogo com o público participante.

Nesse sentido, é preciso dizer que o tema da conservação da onça parda não emergiu da própria comunidade, mas foi um tema apresentado às pessoas participantes desta pesquisa, diante das constatações sobre as ameaças que a espécie vem sofrendo na região e da possibilidade de conflitos entre esses animais e a população rural. Assim, dispúnhamos de justificativas para propor o tema para a comunidade e para a equipe de educadoras(es). Ao mesmo tempo, nos propusemos, de início, dialogar sobre a pertinência deste tema na visão das pessoas participantes da pesquisa e, por fim, analisar coletivamente as possibilidades de associação com outros temas relevantes para a realidade local. Acreditamos que esse movimento caracteriza uma perspectiva comunicativa, em que pessoas com diferentes vivências e visões de mundo podem argumentar livremente sobre determinado tema, buscando o entendimento e contribuindo para um objetivo comum que venha a ser legitimado pelo grupo.

\section{Agradecimentos}

Agradecemos às/aos participantes da pesquisa, ao Conselho Nacional de Desenvolvimento Científico e Tecnológico $(\mathrm{CNPq})$ e à Fundação de Amparo à Pesquisa do Estado de São Paulo (Fapesp) pelo financiamento da Rede Predadores de Topo de Cadeia Sisbiota, à Coordenação de Aperfeiçoamento de Pessoal de Nível Médio (Capes) pela bolsa de doutorado da primeira autora e ao Instituto Florestal por conceder autorização para a realização deste trabalho nas unidades de conservação.

\section{Referências}

ALEGRE, S. I. Talleres comunitarios de educación ambiental para la introducción del pensamiento ambiental a nivel local. DELOS: Desarrollo Local Sostenible, Málaga, v. 1, 2007.

ARAÚJO, R. T. N; KRAEMER, B. M.; MURTA, P. F. O. Percepções ambientais e concepções de estudantes do ensino fundamental de Belo Horizonte/MG sobre tubarões. e-Scientia, Belo Horizonte, v. 4, n. 1, p. 69-79, 2011.

AUBERT, A.; FLECHA, A.; GARCÍA, C.; FLECHA, R.; RACIONERO, S. Aprendizaje dialógico en la Sociedad de la Información. Barcelona: Hipatia, 2008.

BARREDA-LEYVA, N. Vinculando a la comunidad en los conteos de aves rapaces migratorias (Aves: Falconiformes) en el este de Cuba. Ra Ximhai, El Fuerte, v. 6, n. 3, p. 479-495, 2010. 
BATALHA, M. A.; MANTOVANI, W. Reproductive phenological patterns of cerrado plant species at the Pé-de-Gigante Reserve (Santa Rita do Passa Quatro, SP, Brazil): a comparison between the herbaceous and woody floras. Brazilian Journal of Biology, São Carlos, v. 60, n. 1, p. 129-145, 2000.

BENITES, M.; MAMEDE, S. B. Mamíferos e aves como instrumentos de educação e conservação ambiental em corredores de biodiversidade do cerrado, Brasil. Mastozoología Neotropical, Mendoza, v. 15, n. 2, p. 261-271, 2008.

BIZERRIL, M. X. A.; SOARES, C. C.; SANTOS, J. P. Linking community communication to conservation of the maned wolf in central Brazil. Environmental Education Research, New York, v. 17 , n. 6 , p. 815-827, 2011.

BONOTTO, D. M. B. Contribuições para o trabalho com valores em educação ambiental. Ciência \& Educação, Bauru, v. 14, n. 2, p. 295-306, 2008.

BRAGA, F. M.; GABASSA, V.; MELLO, R. R. Aprendizagem dialógica: ações e reflexões de uma prática educativa de êxito para todos(as). São Carlos: EdUFSCar, 2010.

BRASIL. Lei $n^{\circ}$ 9.985, de 18 de julho de 2000. Regulamenta o art. 225, § 1o, incisos I, II, III e VII da Constituição Federal, institui o Sistema Nacional de Unidades de Conservação da Natureza e dá outras providências. Diário Oficial da União: seção 1, Brasília, DF, 19 jul. 2000. Disponível em: https://bit.ly/1bPMrfW. Acesso em: 7 mar. 2014.

CARVALHO, L. M. A. A temática ambiental e o processo educativo: dimensões e abordagens. In: CINQUETTI, H. C.; LOGAREZZI, A. (Orgs.). Consumo e resíduos: fundamentos para o trabalho educativo. São Carlos: EdUFSCar, 2006. p. 19-41.

CASTILlO, A. Comunicación para el manejo de ecosistemas. Tópicos em Educación Ambiental, México, DF, v. 3, n. 9, p. 58-71, 2003.

CURTI, M.; VALDEZ, U. Incorporating community education in the strategy for harpy eagle conservation in Panama. The Journal of Environmental Education, New York, v. 40, n. 4, p. 3-16, 2009.

DREYFUS, A.; WALS, A. E. J.; VAN WEELIE, D. Biodiversity as a postmodern theme for environmental education. Canadian Journal of Environmental Education, Montreal, n. 4, p. 155-176, 1999.

ESPINOSA, S.; JACOBSON, S. K. Human-wildlife conflict and environmental education: evaluating a community program to protect the Andean bear in Ecuador. The Journal of Environmental Education, New York, v. 43, n. 1, p. 55-65, 2011.

FELGA, A. P.; VALENTI, M. W.; OLIVEIRA, H. T. Limites e possibilidades da educação ambiental para a conservação da biodiversidade com funcionárias/os de uma unidade de conservação (Estações Ecológica e Experimental de Itirapina, SP). In: SIMPÓSIO BRASILEIRO SOBRE O PAPEL FUNCIONAL DOS PREDADORES DE TOPO DE CADEIA, 1., 2013, São Carlos. Anais [...]. São Carlos: UFSCar, 2013.

FLECHA, J. R. Compartiendo palabras: el aprendizaje de las personas adultas a través del diálogo. Barcelona: Paidós, 1997.

FREIRE, P. Extensão ou comunicação? Rio de Janeiro: Paz e Terra, 1977. 
FREIRE, P. Pedagogia da esperança: um reencontro com a Pedagogia do oprimido. Rio de Janeiro: Paz e Terra, 1992.

FREIRE, P. Pedagogia da autonomia: saberes necessários à prática educativa. São Paulo: Paz e Terra, 1996.

FREIRE, P. À sombra dessa mangueira. São Paulo: Olho d’Água, 2001.

FREIRE, P. Pedagogia do oprimido. Rio de Janeiro: Paz e Terra, 2005.

GÓMEZ, J.; LATORREM, A.; SÁNCHES, M.; FLECHA, R. Metodología comunicativa crítica. Barcelona: El Roure, 2006.

GÓMEZ, A.; PUIGVERT, L.; FLECHA, R. Critical communicative methodology: informing real social transformation through research. Qualitative Inquiry, London, v. 17, n. 3, p. 235-245, 2011.

GUIMARÃES, M. Educação ambiental e gestão para a sustentabilidade. In: SANTOS, J. E.; SATO, M. (Orgs.). A contribuição da educação ambiental à esperança de Pandora. São Carlos: Rima, 2001. p. 183-195.

GUIMARÃES, M. Educação ambiental crítica. In: BRASIL. Identidades da educação ambiental brasileira. Brasília, DF: Ministério do Meio Ambiente, 2004. p. 25-34.

IARED, V. G.; OLIVEIRA, H. T. Formação de valores estéticos e éticos e o cerrado. In: ENCONTRO PESQUISA EM EDUCAÇÃ̃ AMBIENTAL, 7., 2013, Rio Claro. Anais [...]. Rio Claro: Unesp, 2013. Disponível em: https://bit.ly/2MYbCSQ. Acesso em: 13 maio 2018.

LOGAREZZI, A. J. M. Educação ambiental em resíduo: uma proposta de terminologia. In: CINQUETTI, H. C.; LOGAREZZI, A. (Orgs.). Consumo e resíduo: fundamentos para o trabalho educativo. São Carlos: EdUFSCar, 2006. p. 85-118.

LOGAREZZI, A. J. M. Discutindo a inteligência cultural diante da percepção socioambiental em contexto de comunidade de aprendizagem. In: CONGRESSO LUSO-AFRO-BRASILEIRO DE CIÊNCIAS SOCIAIS, 10., 2009, Braga. Anais [...]. Braga: Universidade do Minho, 2009. p 1-15. 1 CD ROM.

LOGAREZZI, A. J. M. Educação ambiental em comunidades de aprendizagem: uma abordagem crítico-dialógica. In: REUNIÃO ANUAL DA ANPED, 33., 2010, Caxambu. Anais [...]. Caxambu: ANPED, 2010. 1 CD-ROM.

MARCHINI, S.; MACDONALD, D. W. Predicting ranchers' intention to kill jaguars: case studies in Amazonia and Pantanal. Biological Conservation, Amsterdam, v. 147, n. 1, p. 213-221, 2012.

MARIN, A. A.; OLIVEIRA, H. T.; COMAR, V. A educação ambiental num contexto de complexidade do campo teórico da percepção. Interciencia, Caracas, v. 28, n. 10, p. 616-619, 2003.

MARIN, A. A.; SILVEIRA, E. Cosmos e locus: dos significados da cidadania planetária à construção de mitos positivos do cotidiano no discurso da educação estética ambiental. OLAM, Rio Claro, v. 9, n. 2, p. 164-186, 2009.

MELlO, R. R.; BRAGA, F. M.; GABASSA, V. Comunidades de aprendizagem: outra escola é possível. São Carlos: EdUFSCar, 2012. 
MENARIN, C. A. À sombra dos jequitibás: patrimônio ambiental e políticas públicas na criação e implantação do Parque Estadual de Vassununga/SP (1969-2005). 2009. Dissertação (Mestrado em História e Sociedade) - Faculdade de Ciências e Letras de Assis, Universidade Estadual Paulista, Assis, 2009.

MIOTTO, R. A. et al. Genetic diversity and population structure of pumas (Puma concolor) in southeastern Brazil: implications for conservation in a human-dominated landscape. Conservation Genetics, Dordrecht, v. 12, n. 6, p. 1447-1455, 2011.

MIOTTO, R. A. et al. Monitoring a Puma (Puma concolor) population in a fragmented landscape in southeast Brazil. Biotropica, [S. l.], v. 44, n. 1, p. 98-104, 2012.

MYERS JR., O. E.; SAUNDERS, C. D. Animals as links toward developing caring relationships with natural world. In: KAHN JR., P. H.; KELLERT, S. R. (Eds.). Children and nature: psychological, sociocultural and evolutionary investigations. London: The MIT Press, 2002. p. 153-178.

OKSANEN, M. The moral value of biodiversity. Ambio, [S. l.], v. 26, n. 8, p. 541-545, 1997.

OLIVEIRA, H. T. Transdisciplinaridade. In: BRASIL. Encontros e caminhos: formação de educadoras(es) ambientais e coletivos educadores. Brasília, DF: Ministério do Meio Ambiente, 2005. p. 333-343.

PADUA, S. M. Primate conservation: integrating communities through environmental education programs. American Journal of Primatology, Hoboken, v. 72, n. 5, p. 450-453, 2010.

RIBEIRO, C. L. Educação ambiental e aprendizagem dialógica: possibilidades e limites para a transformação da escola e seu entorno. 2009. Dissertação (Mestrado em Educação) - Centro de Educação e Ciências Humanas, Universidade Federal de São Carlos, São Carlos, 2009.

RIBEIRO, C. L.; SANT'ANA, F. M. G.; LOGAREZZI, A. J. M. Contribuciones del aprendizaje dialógico para las prácticas escolares de educación ambiental. In: MULTIDISCIPLINAR CONGRESS OF EDUCATIONAL RESEARCH, 2012, Barcelona. Anais [...]. Barcelona: CIMIE, 2012. 1 CDROM.

RIPPLE, W. J. et al. Status and ecological effects of the world's largest carnivores. Science, New York, v. 343, n. 6167, p. 1241-1484, 2013.

SANT'ANA, F. M. G. Contribuições da aprendizagem dialógica para a educação ambiental e suas possiveis convergências. Dissertação (Mestrado em Educação) - Centro de Educação e Ciências Humanas, Universidade Federal de São Carlos, São Carlos, 2011.

SANTOS, J. E.; SATO, M.; PIRES, J. S. R.; MAROTI, P. S. Environmental education praxis toward a natural conservation area. Revista Brasileira de Biologia, São Carlos, v. 60, n. 3, p. 361-372, 2000.

SÃO PAULO (Estado). Secretaria do Meio Ambiente. Plano de manejo integrado: estações ecológica e experimental de Itirapina/SP. São Paulo: Instituto Florestal, 2006.

SÃO PAULO (Estado). Diretrizes para a conservação e restauração da biodiversidade no estado de São Paulo. São Paulo: Programa Biota/Fapesp: Secretaria do Meio Ambiente, 2008.

SERGIO, F. et al. Top predators as conservation tools: ecological rationale, assumptions, and efficacy. Annual Review of Ecology, Evolution and Systematics, [S. l.], v. 39, p. 1-19, 2008. 
SIMBERLOFF, D. Flagships, umbrellas, and keystones: is single-species management passé in the landscape era? Biological Conservation, Amsterdam, v. 83, n. 3. p. 247-257, 1998.

TALAMONI, S. A.; MOTTA JUNIOR, J. C.; DIAS M. M. Fauna de mamíferos da Estação Ecológica de Jataí e da Estação Experimental de Luiz Antônio. In: SANTOS, J. E.; PIRES, J. S. R. (Eds.). Estudos integrados em ecossistemas, Estação Ecológica de Jataí. São Carlos: Rima, 2000. v. 1, p. 317-329.

TOZONI-REIS, M. F. C. Temas ambientais como "temas geradores": contribuições para uma metodologia educativa ambiental crítica, transformadora e emancipatória. Educar em Revista, Curitiba, v. 27, p. 93-110, 2006.

VALENTI, M. W. Educação ambiental e biodiversidade em unidades de conservação: mapeando tendências. 2010. Dissertação (Mestrado em Ecologia e Recursos Naturais) - Centro de Ciências Biológicas e Saúde, Universidade Federal de São Carlos, São Carlos, 2010.

VALENTI, M. W.; MIOTTO, R. A.; OLIVEIRA, H. T.; OLIVEIRA, S. M. Educação ambiental e a conservação da onça parda: potenciais das unidades de conservação do nordeste paulista. Revista do Instituto Florestal, São Paulo, v. 26, n. 1, p. 55-69, 2014.

VALENTI, M. W.; OLIVEIRA, H. T.; LOGAREZZI, A. J. M. Exclusory and transformative dimensions of adult environmental education in two Brazilian protected areas. Environmental Education Research, New York, v. 23, n. 5, p. 675-686, 2017.

VAN DER PLOEG, J.; ARANO, R. R.; VAN WEERD, M. What local people think about crocodiles: challenging environmental policy narratives in the Philippines. The Journal of Environment \& Development, London, v. 20, n. 3, p. 303-328, 2011.

VAN DER PLOEG, J.; CAUILLAN-CUREG, M.; VAN WEER, M.; PERSOON, G. "Why must we protect crocodiles?" Explaining the value of the Philippine crocodile to rural communities. Journal of Integrative Environmental Sciences, New York, v. 8, n. 4, p. 287-298, 2011.

WALS, A. E. J. Environmental education and biodiversity: ICK-report n. 36. Wageningen: National Reference Centre for Nature Management, 1999.

WALS, A. E. J.; DILLON, J. Conventional and emerging learning theories: implications and choices for educational researchers with a planetary consciousness. In: STEVENSON, R.B.; BRODY, M.; DILLON, J.; WALS, A. E. J. (Eds.). International Handbook of Research on Environmental Education. New York: AERA, 2013. p. 253-261.

WALS, A. E. J.; VAN WEELIE, D. Environmental education and the learning of ill-defined concepts: the case of biodiversity. South African Journal of Environmental Education, Wageningen, n. 17, p. 411, 1997. 